PAPER

\title{
Defending the four principles approach as a good basis for good medical practice and therefore for good medical ethics
}

\author{
Raanan Gillon
}

\begin{abstract}
Correspondence to
Professor Raanan Gillon, Department of Primary Care and Public Health, Imperial College London, Charing Cross Campus, London W6 8RP, UK or 42 Brynmaer Road, London, SW11 4EW, UK;

raanan.gillon@imperial.ac.uk
\end{abstract}

Accepted 30 October 2014

\begin{abstract}
This paper argues that the four prima facie principlesbeneficence, non-maleficence, respect for autonomy and justice-afford a good and widely acceptable basis for 'doing good medical ethics'. It confronts objections that the approach is simplistic, incompatible with a virtuebased approach to medicine, that it requires respect for autonomy always to have priority when the principles clash at the expense of clinical obligations to benefit patients and global justice. It agrees that the approach does not provide universalisable methods either for resolving such moral dilemmas arising from conflict between the principles or their derivatives, or universalisable methods for resolving disagreements about the scope of these principles-long acknowledged lacunae but arguably to be found, in practice, with all other approaches to medical ethics. The value of the approach, when properly understood, is to provide a universalisable though prima facie set of moral commitments which all doctors can accept, a basic moral language and a basic moral analytic framework. These can underpin an intercultural 'moral mission statement' for the goals and practice of medicine.
\end{abstract}

Not long after I first read the 1979 first edition of Principles of Biomedical Ethics, ${ }^{1}$ currently in its 2013 seventh edition, I became convinced that those four prima facie principles-beneficence, non-maleficence, respect for autonomy and justice -afforded a good and widely acceptable basis for 'doing good medical ethics'. Over the years I have promoted and defended their use, while acknowledging that being prima facie they did not provide universalisable methods for resolving conflicts between those principles or their derivatives, nor did they provide a universalisable method or methods for resolving conflicts about their proper scope of application. ${ }^{2-5}$ Intermittently I have incorporated them into a proposed intercultural 'moral mission statement' for the goals of medicine: 'the provision of health benefits with minimal harm in ways that respect people's deliberated choices for themselves and that are just or fair to others, whether in the context of distribution of scarce resources, respect for people's rights or respect for morally acceptable laws'. ${ }^{5}$

In writing my own contribution to this 40th anniversary issue of the Journal of Medical Ethics (JME40) I have had the privilege of being its co-guest editor-a delightful if demanding reminder of my 20 years as its editor until 2001.
My reading of all the other fascinating accounts in this issue of what it is to do good medical ethics has been of enormous benefit to me when writing this contribution, now as author not editor. Knowing that the four principles approach had over the years encountered some vigorous opposition, I was keen to discover if the cornucopia of views about medical ethics in this issue would shake my confidence in these principles or in my proposed 'moral mission statement' for the goals of medicine. In particular, would I encounter any well reasoned arguments for rejecting any one of these prima facie principles or for the need to add any additional universalisable moral concerns that cannot be captured by one or some combination of these principles?

Certainly a few of the contributors to this issue are unhappy about the four principles approach, or principlism as it is now commonly called. Most vigorous of the critics is Rosamond Rhodes ${ }^{6}$ who criticises principlism with words and phrases such as incoherent, not illuminating, simplistic, confusing, formulaic, requiring rotewise ticking off, unproductive, distracting. Wing May Kong ${ }^{7}$ too under the heading 'Tick Box Ethics' complains that 'Principlism, and in particular, a simplistic version in which it is reduced to a flowchart approach denuded of nuanced reasoning, seems to have become dominant in medical ethics, at least amongst health professionals'. Angus Dawson, ${ }^{8}$ as a philosopher specialising in public health ethics, complains that 'the medical ethics literature tends to invoke a narrow range of values, largely concentrated on individualistic considerations, with a predominant focus on autonomy ... This can result in the marginalisation of more societal, population or community values and perspectives'. Similar issues are discussed by Richard Cookson, ${ }^{9}$ who argues that medical ethics should be concerned not only about 'the identified patients who benefit from decisions, but also the unidentified patients who bear the opportunity costs'. Jennifer Prah Ruger ${ }^{10}$ argues that medical ethics must lift its eyes towards global ethics and a worldwide concern to promote "health capabilities and specifically central health capabilities-freedom from avoidable morbidity and premature death', as underpinning 'the capability to flourish' which itself is 'the proper goal of social and political activity'. A different type of concern about principlism in some of these papers is its perceived lack of focus on the emotional, imaginative and virtue-related aspects of medical ethics-perhaps most vividly 
conveyed in Paquita de Zulueta's paper, in which she argues for medical ethics to be based on the virtues rather than on principles and especially on the key medical virtue of compassion for those who are suffering. ${ }^{11}$ But one of the most important concerns in this collection is how to implement 'good medical ethics' so that it is actually practised-with principlism getting part of the blame from Kong and Rhodes-though it seems clear that their attacks are largely directed at the mis-use of principlism, which is a real problem though not I think for principlism so much as for medical education. And so to 'the charge list'.

In answer to my first question to myself, not one of the 35 papers rejects any one of the four prima facie principles-that in itself seems to me to be a very important starting point for medical ethics! In my experience over the last 30 years people have occasionally said they reject respect for autonomy, but further 'socratic' questioning revealed that either they thought it meant 'I want it so I get it', or that what they really meant was that the principle was given too much weight. That concern is expressed in several papers in this issue, concerning its overemphasis at the expense of beneficence to patients, or of global justice, or of preventable harm in general. But principlism does not prescribe the 'weight' that should be given to any of these principles in relation to each other, though unlike Beauchamp and Childress I personally do regard respect for autonomy as 'first among equals, ${ }^{5}$ but 'among equals' remains the case! I'll return to this subject below.

\section{'PRINCIPLISM' AND 'VIRTUISM'}

As to my second question to myself, about additional universalisable moral concerns that cannot be encompassed by one or some combination of the four principles, several contributors at least imply that the four principles approach has no room, or inadequate room, for the virtues. Paquita de Zulueta argues powerfully for replacing principle-based ethics with virtue-based ethics to underpin medical ethics. ${ }^{11}$ Dan Callahan ${ }^{12}$ does not have much time for any ethical theory in medical ethics, but insofar as he has, 'I have been driven back to Aristotle's ethic, which comes down to virtuous citizens making good prudential judgments'. And virtue ethics gets the thumbs up from Justin Oakley. ${ }^{13}$ However, in his paper there are indications that his approach to virtue ethics would have no trouble in accepting the four prima facie principles. For example, he argues that a proposal that doctors are honest with patients

'about any financial or other ties with the pharmaceutical and medical device industries can be justified as an exercise of the generic professional virtue of honesty, and as thereby meeting the ethical demand to respect patient autonomy (as a sideconstraint on the requirement to serve the best interests of one's patients)'.

A concern that principlism is at odds with or ignores a virtuebased approach to medical ethics really is not borne out by the facts. Certainly I have myself recurrently argued that good or virtuous characters are essential to the moral life; as I wrote in 1984:

\footnotetext{
I have never heard of any moral philosopher, and especially of any moral philosopher particularly interested in medical ethics, who is in any way opposed to the encouragement of good character, integrity and a well developed conscience. What many philosophers are opposed to is any assumption that these features can be sufficient even for moral development let alone for medical or any other sorts of ethics. ${ }^{2}$
}

In a more extended discussion in 1998 I was keen on 'reconciling principles and virtues in medical ethics', citing with approval the view of virtue-ethics-orientated Pellegrino and
Thomasma that 'you can't have one without the other' (pp. 46-50). ${ }^{4}$ Beauchamp and Childress go to far greater lengths to emphasise the importance of virtue ethics within principlism, with a chapter on moral character (pp. 30-56) and a substantial section on virtue theory (pp. 375-84). ${ }^{1}$ As they say in their preface to the seventh edition, "We have had a major commitment to virtue theory and moral character since our first edition and over the years we have expanded our discussion of these topics'. So it is simply mistaken to accuse principlism of not making room for virtue ethics (or 'virtuism' as I have dubbed such accounts (p. 309) $)^{5}$ ). Beauchamp and Childress and I diverge in our explanations of the relationship of virtues and principles in that my account has not (so far?) located virtues in 'the common morality'. I have simply argued that the four principles are available to help differentiate those character dispositions that are morally desirable and therefore virtuous from those that are morally undesirable and therefore vicious and from those that are morally neutral. If eudaimonia or human flourishing or agape is the ultimate moral standard against which character dispositions are to be categorised as virtuous, ${ }^{14}$ then I have suggested that

character dispositions that conduce to the creation of benefits, the avoidance or minimisation of harms, respect for people's autonomy and a striving for justice may reasonably be claimed to be character traits that conduce to eudaimonia, human flourishing or agape, and should thus be categorised as virtues (and the converse for vices) (p. 309). ${ }^{5}$

Both my account and the more extensive account given by Beauchamp and Childress give great weight to the importance of the virtues in the moral life.

\section{COMPASSION AND HUMANITY}

In the context of de Zulueta's emphasis on the importance of the virtue of compassion in medical ethics, I can only plead my 'principlist' agreement, although I prefer to use the term 'humanity' for the cluster of virtues involved ('compassion' has for me the slight disadvantage of its Lady Bountiful connotations-but it is little more than a personal preference). Along with her I have argued for the need to restore humanity in healthcare. I use a simple 'fast ethics' four principles analysis to support the ethical desirability of humanity in healthcare-'fast ethics' because the problem is not about coming to that obvious conclusion but how to get the conclusion implemented in practice, about which I offered some suggestions. ${ }^{15}$ That problem, of translating ethical theory into ethical practice is, of course, as Kong argues in her contribution, a major one-but unlike her I think principlism properly used would actually help to ameliorate the problem! In a nutshell, if medical students and doctors were actually taught and encouraged to commit themselves to the simply expressed minimal objective of trying to live their professional lives in ways that are consistent with those four prima facie principles and with the medical moral mission statement above which is underpinned by those principles, I am pretty sure that this would indeed help them to be good and compassionate doctors and would thus benefit the patients and communities whom they serve.

\section{TOO MUCH WEIGHT FOR AUTONOMY?}

Several contributors echo widespread claims that respect for autonomy is given too much weight either at the expense of beneficence, for example Kong, ${ }^{7}$ Boyd, ${ }^{16}$ Hurwitz $^{17}$ and Callahan, ${ }^{12}$ or at the expense of justice, for example Dawson, ${ }^{8}$ 
Cookson, ${ }^{9}$ Prah Ruger ${ }^{10}$ and Callahan, ${ }^{12}$ or at the expense of non-maleficence, for example Savulescu. ${ }^{18}$ These concerns point to the general problem of how to deal with conflict between these principles. First let me reiterate that to criticise the relative weights accorded to the different principles is not to reject their prima facie importance.

However, as one who argues (unlike Beauchamp and Childress) that of those four prima facie principles respect for autonomy is 'first among equals', I must directly address the complaint that respect for autonomy is given excessive weight. According to Callahan, medical ethics has, since the 1970s, been 'the main purveyor' of respect for autonomy which 'intended or not' has been transmuted into 'an ethics of choice' at the cost of doing 'what is good for patients, now deftly set aside with an emphasis on the rights of patients'. Kong ${ }^{7}$ asks 'for example should a doctor simply accept the informed but poor choice of a patient on the grounds of respecting autonomy? Or is there an ethical obligation to persuade him otherwise and if so where does this obligation arise from?' Hurwitz, ${ }^{17}$ referring to my 'first among equals' paper, remarks 'Beneficence is so often watered down by respect for autonomy - that "first among equals" of moral principles running counter to it ... that one wonders how determinative it may be of good health care'. Similar complaints are echoed by several other contributors to JME40. Other contributors, as stated above, argue that 'individualistic' concerns for individual autonomy are given too much weight when it conflicts with justice, including concerns for fair distribution of healthcare globally, a claim that is given considerable support by Beauchamp and Childress themselves who argue that 'a globalised world has brought a realisation that protecting health and maintaining healthy conditions are international in nature and will require a justice-based restructuring of the global order' (p. 277). ${ }^{1}$

But the fact that principlism in itself does not provide a universalisable method for prioritising the four principles, far from being a fatal blow to principlism, is on the contrary a major advantage. Given that there is no widely acceptable universalisable method for prioritising these principles (pace the competing claims to the contrary from utilitarians, Kantians, virtuists, feminists, phenomenologists and several others), it is a positive 'virtue' of principlism that it allows-partly precisely because of the principle of respect for autonomy-for different people and different cultures to give different weight to these different principles when they conflict. As I wrote in my 'first among equals' paper, 'Having avowed my own tendency to emphasise respect for autonomy, let me reiterate that the actual use made of the four principles approach can legitimately vary from person to person, culture to culture'. 5 As many contributors point out in this issue, doctors have a professional obligation to benefit their patients. This obligation is in my own view the core moral commitment of doctors-their core 'Hippocratic' objective ${ }^{4}$ or their 'Hippocratic moral commitment'. 5 As Kong and others also point out, respect for autonomy may conflict with this objective. From a broader perspective, other contributors are also concerned to provide health benefits, but not just to those patients lucky enough to be already embraced within the Hippocratic objective of clinicians, but to the millions globally who do not have doctors. Essentially respect for autonomy is seen by both sorts of objectors as restraining the provision of health benefit, either to their patients in the case of clinicians or to sick people throughout the world who do not have clinicians. But conversely in both cases, respect for autonomy is an important moral constraining principle, both on paternalistic clinical beneficence, and on paternalistic global beneficence-and in both cases the relative weight to give to beneficence or to respect for autonomy is contended and requires negotiation and agreement.

Thus in the clinical context, respect for autonomy may constrain the Hippocratic commitment when doctors are not given permission by their patients to treat them beneficially. But it is surely the role of doctors to offer autonomous patients their beneficial services, not to impose them. Here respect for autonomy functions as a moral brake on the imposition of beneficence against an autonomous person's wishes-a particularly important function in medical practice for which the Hippocratic commitment was until recent times widely misinterpreted by doctors as a moral license for imposed medical paternalism. When I was a medical student, doctors issued and their patients tended to accept 'doctor's orders'-medical ethics has contributed to there being less of this! To a degree the Hippocratic moral commitment itself requires, in the case of autonomous patients, that their autonomy is respected, simply because people's assessment of harms and benefits is in part subjective and idiosyncratic-so for doctors to be able to decide what course of action actually does provide net benefit with minimal harm they need to consult their autonomous patients. It would be an arrogant doctor indeed who decided that he knows better than the Jehovah's Witness patient about whether or not a blood transfusion would produce for that patient net benefit over harm-or even net health benefit, though this last claim requires more sophisticated analysis about the meaning of health, its relation to wellbeing, and whether people's perceptions of their spiritual health are to be allowed to count. Yes, sometimes autonomous patients decide to ignore or reject their doctors' sensible advice, even if they may agree that following it would be beneficial. Respect for autonomy should allow one to make such decisions.

Nonetheless that Hippocratic commitment remains a moral commitment which does indeed create a duty to try to persuade such patients to pursue the medical course of action that they believe to be most beneficial and least harmful. But try to persuade is the relevant formulation. Thus to Kong's questions 'Or is there an ethical obligation to persuade him otherwise and if so where does this obligation arise from?', my response is 'yes there is an obligation to try to persuade him otherwise-but there is not an obligation to persuade him otherwise'- the distinction is in my view morally crucial. As for where this obligation comes from, it comes from the voluntary decision of doctors to become part of the medical profession and thus to commit themselves to accepting that professional Hippocratic commitment to produce net health benefit with minimal harm for those they serve-in the case of therapeutic doctors their patients, in the case of public health doctors their communities.

\section{A pernicious mistake}

Having said all that, misunderstanding respect for autonomy to mean 'I want it so you have to give it me' is a pernicious mistake that when accepted does indeed threaten to undermine that core Hippocratic goal of medicine, both in clinical medicine and as it relates to its distribution via public and global health.

Four reminders are relevant. The first concerns the etymology of the word 'autonomy': it means self-rule not rule of others. Autonomous refusal of treatment is self-rule. Autonomous request for treatment seeks and requires autonomous consent from the person requested who may justifiably decline consent. The second reminder is that autonomy requires deliberation-it is about thought-out or deliberated self-rule. Autonomy is not simple choice and choice is not necessarily autonomous The third reminder recalls that respect for autonomy requires equal respect 
for the autonomy of all potentially affected, in whichever philosophical tradition it is found-in the Kantian version treating people as 'ends in themselves', in the utilitarianism of JS Mill respecting people's self-determination. And the fourth reminder is that within the four principles approach respect for autonomy is a prima facie moral principle. Even if it is accepted to be 'first among equals' it remains 'among equals' and may in particular cases and types of case have to give way to one or more of the other three moral principles of beneficence, non-maleficence and justice (just as prime ministers, to whom the phrase is more usually applied, may have to give way to their cabinet colleagues). Again of course 'good medical ethics' requires thorough philosophical analysis of these issues, including the competing accounts of what is meant by autonomy and respect for autonomy.

The practical normative requirements of respect for autonomy are vigorously debated. Nonetheless it is probably safe to claim that in much contemporary Western medicine respect for patients' autonomy requires doctors, at least in normal nonemergency situations, to give patients adequate information before they provide any treatment or other intervention, to ask for consent for such treatment, and to respect refusals of proposed interventions by adequately autonomous patients. When it comes to patients' autonomous requests for treatments, while it is now widely agreed that these should be properly considered by doctors when assessing what would be most beneficial and least harmful in the particular case, if in the doctor's assessment, having taken the patient's views into account, the treatment cannot be beneficial or will be harmful, then the doctor is permitted to reject the patient's request for that treatment even if it is an autonomous request. Such requests may also be justifiably rejected, even when autonomously made, if countervailing obligations of non-maleficence or of justice-typically distributive or legal justice-supervene.

Other practical norms stemming from respect for autonomy remain comparatively uncontentious. They include strong but not absolute duties of honesty (do not lie and do not intentionally deceive), of confidentiality, and of promise keeping (which as I enjoy reminding medical colleagues includes turning up to appointments on time). But respect for autonomy, even if it is seen as 'first among equals', is only one of those four prima facie principles!

And so to the most vigorous of the attacks on principlism to be found in JME40, those of Rosamond Rhodes ${ }^{6}$ and Wing May Kong. ${ }^{7}$

First, although above I pointed out that among her various accusations against principlism Rhodes accused it of being 'incoherent', she was actually not employing the ordinary English usage of that term, as explained in the jointly authored guest editorial introducing JME40. ${ }^{19}$ Instead she was using the term in a specialised philosophical sense according to which in her view principlism did not 'cohere' with good medical practice. But is she right? I don't think so.

Rhodes writes:

good medical ethics should cohere with what we regard as good medical practice. Regrettably, however, most approaches to medical ethics view the field as an application of common morality. This is famously the case for the methodology advocated by Tom Beauchamp and James Childress. ${ }^{6}$

She goes on to explain:

For example, according to common morality, whatever we see or hear can be shared: Exceptions to that presumption require a promise or a non-disclosure agreement. In medicine, in contrast, confidentiality is the rule. In common morality, beneficence is an imperfect duty: Acts of kindness are nice, but optional. In medicine, however, beneficence is the defining duty, and clinicians are committed to acting for the good of patients and society. ${ }^{6}$

But Beauchamp and Childress go out of their way to distinguish between 'particular moralities', including medicine, which are not universalisable, and 'the common morality' which is universalisable and which they define as 'the set of norms shared by all persons committed to morality' (eg, p. 417). ${ }^{1}$ All particular moralities if they are themselves to be morally acceptable must share the common morality (p. 4), ${ }^{1}$ but provided they do so they may of course quite acceptably go beyond the common morality. Thus the common morality is entirely consistent with - does indeed cohere with-medical commitments to confidentiality and to beneficence to their patients. It is just the case that doctors commit themselves to a more demanding standard of beneficence, confidentiality, and we hope, kindness than is even prima facie obligatory in the common morality. Note, however, that, pace Rhodes, such beneficence must surely be an imperfect duty in medicine as it must be in the common morality, for neither doctors nor any other people have or could have an obligation to benefit everyone who could be benefited-not even prima facie. Thus the scope of beneficence is necessarily limited and is therefore what Kant called 'an imperfect obligation', whether in the common morality or in medical ethics. But I entirely agree with Rhodes that doctors do indeed commit themselves, in that Hippocratic commitment, to a more demanding obligation of beneficence than that universally required of all moral agents. However, this is by no means universally agreed amongst philosophers: my own claim to that effect years ago provoked a vigorous philosophical rebuttal and a lively exchange in this journal. ${ }^{20} 21$

\section{MISUSE OF PRINCIPLISM}

Let me continue my defence against the criticisms of Rhodes and Kong of principlism tout court by separating their criticisms that are based on poor use of the four principles approach from their critique of the approach itself. To make it clear, by the 'four principles approach' I simply mean acceptance of the claim that all doctors involved in delivering healthcare have prima facie moral obligations of beneficence, non-maleficence respect for autonomy and justice and that these are as Beauchamp and Childress put it 'well-suited as a general framework for biomedical ethics' (p. 421). ${ }^{1}$ My own view (unlike Beauchamp and Childress who explicitly state that they make no such claim (p. 421) ${ }^{1}$ ), is that all moral agents whether or not they are doctors or otherwise involved in healthcare have these prima facie moral obligations; but in the context of answering the question 'what is it to do good medical ethics', my claim is limited to the ethical obligations of doctors.

It is clear that when their criticisms are of 'simplistic' use of the four principles approach they are shooting misleading messengers, the mis-users of principlism, rather than the message itself, which is principlism. Thus Rosamond Rhodes states:

many people rely on a simplistic version of the four principles approach for adjudicating medical ethics dilemmas. Typically, they list the ways in which each principle is related to the decision at hand. As Clouser and Gert pointed out in their insightful article, 'A Critique of Principlism,'... the four principles do not provide a mechanism for resolving dilemmas. Similarly, the four topics approach advocated by Albert Jonsen, Mark Siegler, and William Winslade ... offers no guidance for how to use the collected information to adjudicate a problem. ${ }^{6}$ 
People who rely on 'simplistic versions' of anything are by definition not doing the thing properly. The very use of the term suggests that whatever it is can be done properly and it is notable that Rhodes does not accuse Beauchamp and Childress of being 'simplistic'. Kong also attacks simplistic interpretations when she writes 'Principlism, and in particular, a simplistic version in which it is reduced to a flowchart approach denuded of nuanced reasoning, seems to have become dominant in medical ethics, at least amongst health professionals'. I'll simply agree that simplistic versions of principlism are undesirable, as are, by definition, simplistic versions of anything. But let me add that while 'simplistic' designates excessive and therefore undesirable simplicity, appropriate simplicity in ethics is highly desirable provided it is not simplistic: ethics is there for every moral agent to use, not just people with doctorates. Thus while sometimes 'fast ethics' with simple principlist analysis is I argue appropriate, ${ }^{15}$ sometimes more painstaking 'slow ethics'-complex and nuanced ethics as Kong rightly says-is needed. Whether or not my own 'slow ethics' analysis of a particular case using the four principles would pass muster in this regard, (pp. 165-185), ${ }^{22}$ it is surely undeniable that the principlism of Beauchamp and Childress is sufficiently complex and nuanced. ${ }^{1}$

But of course most readers will have encountered simplistic, even crass misuse of the four principles approach, which often does involve unreflective use of a tick box approach. But surely this is a problem more to do with medical education than with principlism? I am not an education expert but I have found that the four principles approach can be taught in a way that is found helpful in undergraduate and in postgraduate medical education. For a start, although Principles of Biomedical Ethics ${ }^{1}$ is a hefty read, it is well worth taking the trouble to read it! The website for the book is also helpful. ${ }^{23}$ Perhaps, too, international collaborative medical education research projects would be valuable into how the basic framework of principlism can be helpfully incorporated into medical ethics education, undergraduate and postgraduate, in ways that avoid its misuse and enhance the thoughtful and nuanced reflection that we all desire. A preliminary idea for such a project might be to compare, within current education programmes that do not use principlism, a sector within the same programme to which a principlist framework has been added.

\section{MORAL DILEMMAS, SPECIFICATION AND BALANCING}

Rhodes's most important criticism is that 'the four principles do not provide a mechanism for resolving dilemmas'. This is perfectly true and an acknowledged lacuna as I stated at the beginning of this paper and have always stated since the early 1980 s (p. viii). ${ }^{2}$ Of course Beauchamp and Childress, though they accept that there will always be a residue of moral dilemmas ('Explicit acknowledgment of such dilemmas helps deflate unwarranted expectations about what moral principles and theories can do' (pp. 12-13) ${ }^{1}$ ), go far further than I have ever done to propose ways of filling this lacuna, especially by advocating and using examples of specification and balancing. The principles, they explain, 'are general guidelines for the formulation of more specific rules' (p. 13) ${ }^{1}$; and in particular cases of conflict between the principles or between different specifications of the principles 'balancing' is often required. This requires 'deliberation and judgment' (p. 20), ${ }^{1}$ exercise of virtues such as 'sympathetic insight, humane responsiveness and the practical wisdom of discerning a particular patient's circumstances and needs' ( $p$. 22). ${ }^{1}$ They also offer ways of addressing some problematic issues of scope in their chapter on moral status (pp. 62-100). ${ }^{1}$ But while it is true of my own work that it offers 'no guidance for how to use the collected information to adjudicate a problem', it certainly is not true of principlism's canonical account ${ }^{1}$ (it is not quite clear in the above quotation if principlism was included in this 'no guidance' criticism by Rhodes of the four-quadrant method but her use of 'Similarly' suggests that it was). Thus Beauchamp and Childress propose six conditions for the proper exercise of what they call 'balancing' (though I would prefer simply to call it 'reflective judgment') for use when conflicting moral considerations occur in practice. These are (1) that good reasons can be offered for preferring to over-ride the infringed norm rather than the over-riding norm; (2) that there is a realistic prospect of achieving the desired moral objective; (3) that no morally preferable alternative is available; (4) that there is as little infringement as possible compatible with achieving the desired goal; (5) that all negative effects of the infringement have been minimised; and (6) that all affected parties have been treated impartially (pp. 22-23). ${ }^{1}$

Let me add that the approach to dilemmas that Rhodes briefly recommends in alleged contrast to principlism is both sensible and entirely consistent with principlism. Thus she writes:

It is more useful to help the team identify the specific issues that create the dilemma and elicit information that is relevant to resolving the matter. It is then important to offer reasons for prioritising one important concern over the other. And when no particular resolution is obvious, clinicians should be helped to identify additional facts that could inform a decision about which path to take. ${ }^{6}$

Nothing in Principles of Biomedical Ethics conflicts with this advice and item (1) in the list of conditions for balancing noted above is very similar to Rhodes's advice to 'offer reasons for prioritising one important concern over another'.

\section{CONCLUSION}

I have confronted objections to principlism or the four principles approach to be found in this 40th anniversary issue of the journal addressing the question 'What is it to do good medical ethics?' I have agreed that it is sometimes misused, sometimes simplistically so; that respect for autonomy is sometimes mistakenly assumed always to trump the other principles and sometimes mistakenly assumed to mean that if someone autonomously wants something he or she should be given it. I have agreed too that understanding the four principles approach does not necessarily lead to better medical practice, and that virtues are undoubtedly an essential part of the moral life. I have also agreed that it does not provide a universalisable method either for dealing with moral dilemmas or for dealing with fundamental disagreements about the proper scope of these principles-but nor are there currently any other such methods that are both universalisable and widely accepted. I have argued that none of these features undermines the acceptance of principlism or the four principles approach-when properly understood-as affording a good and useful moral framework for doing good medical ethics. It is a framework that is compatible with other universalisable ethical approaches, including deontological, utilitarian and virtuist approaches, as well as several others (pp. 183-185). ${ }^{22}$ Most importantly, it provides a universalisable set of prima facie moral commitments to which all doctors can subscribe, whatever their culture, religion (or lack of religion), philosophy or life stance; in addition it provides a basic moral language and a basic moral analytic framework that all interested in biomedical ethics can share. It can properly underpin the 'moral mission statement' for the goals of medicine with which I started this paper. 


\section{JME40: Good medical ethics}

\section{Competing interests None.}

Provenance and peer review Commissioned; internally peer reviewed.

\section{REFERENCES}

1 Beauchamp T, Childress J. Principles of Biomedical Ethics. 1st edn. New York, Oxford: Oxford University Press, 1979. All subsequent references and page numbers refer to the 7th edition, 2013.

2 Gillon R. Philosophical Medical Ethics. Chichester: Wiley, 1985.

3 Gillon R. Medical ethics: four principles plus attention to scope. BMJ 1994;309 (6948):184-8.

4 Gillon R. What is medical ethics' business? In: Evans M. ed. Critical Reflections on Medical Ethics. Vol 4. Advances in Bioethics 1998:31-50.

5 Gillon R. Ethics needs principles - four can encompass the rest-and respect for autonomy should be 'first among equals'. J Med Ethics 2003;29:307-12.

6 Rhodes R. Good and not so good medical ethics. J Med Ethics 2015;41:71-4.

7 Kong WM. What is good medical ethics? A clinician's perspective J Med Ethics 2015;41:79-82.

8 Dawson A. Ebola — what it tells us about medical ethics. J Med Ethics 2015;41:107-10.

9 Cookson R. Justice and the NICE approach. J Med Ethics 2015;41:99-102.

10 Prah Ruger J. Good medical ethics, justice and provincial globalism. J Med Ethics 2015:41:103-6.

11 de Zulueta P. Suffering, compassion and 'doing good medical ethics'. J Med Ethics 2015:41:87-90.
12 Callahan D. What is it to do good ethics? J Med Ethics 2015;41:68-70.

13 Oakley J. Good medical ethics - from the inside out and back again. J Med Ethics 2015;41:48-51.

14 Campbell A. The virtues and vices of the four principles. J Med Ethics 2003;29: 292-6.

15 Gillon R. Restoring humanity in health and social care-some suggestions. Clin Ethics 2013;8(4):105-10.

16 Boyd K. The impossibility of informed consent? J Med Ethics 2015:41:44-7.

17 Hurwitz B. Medical humanities and medical alterity in fiction and in life. J Med Ethics 2015:41:64-7.

18 Savulescu J. The failure of bioethics: why bioethics needs better philosophy. J Med Ethics [this issue].

19 Gillon $\mathrm{R}$, Higgs $\mathrm{R}$. What is it to do good medical ethics? A kaleidoscope of views. $J$ Med Ethics 2015;41:1-4.

20 Gillon R. Do doctors owe a special duty of beneficence to their patients? J Med Ethics 1986;12:171-3.

21 Downie R. Professional ethics: further comments. J Med Ethics 1986;12: 195-6.

22 Gillon R. Families and genetic testing: the case of Jane and Phyllis from a four-principles perspective. In: Ashcroft R, Lucassen A, Parker M, Verkerk M, Widdershoven G. eds. Case Analysis in Clinical Ethics. Cambridge: Cambridge University Press, 2005:165-85.

23 Principles of Biomedical Ethics. 7th edn. http://www.oup.com/us/beauchamp (accessed 6 Nov 2014). 


\section{Correction}

Gillon R. Defending the four principles approach as a good basis for good medical practice and therefore for good medical ethics. J Med Ethics 2015;41:111-6.

The author misrepresented Beauchamp and Childress when he wrote: 'My own view (unlike Beauchamp and Childress who explicitly state that they make no such claim (p. 421) ${ }^{1}$, is that all moral agents whether or not they are doctors or otherwise involved in healthcare have these prima facie moral obligations; but in the context of answering the question 'what is it to do good medical ethics?' my claim is limited to the ethical obligations of doctors'.

The author intended and should have written the following: 'My own view, unlike Beauchamp and Childress who explicitly state that they make no such claim (p.421) ${ }^{1}$ is that these four prima facie principles can provide a basic moral framework not only for medical ethics but for ethics in general'.

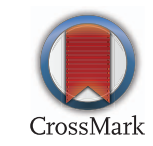

J Med Ethics 2015;41:446. doi:10.1136/medethics-2014-102282corr1 


\section{Correction}

Gillon R. Defending the four principles approach as a good basis for good medical practice and therefore for good medical ethics. J Med Ethics 2015;41:111-6.

The author misrepresented Beauchamp and Childress when he wrote: 'My own view (unlike Beauchamp and Childress who explicitly state that they make no such claim (p. 421) ${ }^{1}$, is that all moral agents whether or not they are doctors or otherwise involved in healthcare have these prima facie moral obligations; but in the context of answering the question 'what is it to do good medical ethics?' my claim is limited to the ethical obligations of doctors'.

The author intended and should have written the following: 'My own view, unlike Beauchamp and Childress who explicitly state that they make no such claim $(p .421)^{1}$ is that these four prima facie principles can provide a basic moral framework not only for medical ethics but for ethics in general'.

J Med Ethics 2015;41:829. doi:10.1136/medethics-2015-102811corr1

\section{Linked}

- http://dx.doi.org/10.1136/medethics-2014-102150

- http://dx.doi.org/10.1136/medethics-2014-102458

http://dx.doi.org/10.1136/medethics-2015-102810

- http://dx.doi.org/10.1136/medethics-2015-102812

- http://dx.doi.org/10.1136/medethics-2015-102814

- http://dx.doi.org/10.1136/medethics-2015-102966 